\title{
Synthesis, characterization, and thermal properties of new flavor compounds
}

\author{
Marta Worzakowska
}

Received: 24 September 2013/ Accepted: 11 November 2013/Published online: 10 December 2013

(C) The Author(s) 2013. This article is published with open access at Springerlink.com

\begin{abstract}
Synthesis, characterization, and thermal properties of new, flavor, long chain esters were presented. The new compounds were obtained in the catalytic esterification process of a stoichiometric ratio of trans-3,7-dimethyl2,6-octadien-1-ol, succinic anhydride, and aliphatic chain diol. As diols ethylene glycol, 1,4-buthylene glycol, 1,5pentylene glycol, and 1,6-hexylene glycol were applied. The spectroscopic analyses completely confirmed that the applied synthesis conditions allowed obtaining the new compounds with high yield and purity. Their thermal properties were studied in inert and oxidative atmospheres. The esters were less thermally stable in inert (IDT $186-195{ }^{\circ} \mathrm{C}$ ) than in oxidative (IDT $210-228^{\circ} \mathrm{C}$ ) atmosphere. Two, non-completely divided decomposition steps were visible during their pyrolysis. In contrast, the new, long chain compounds decompose in three major steps in air. The analyses of the volatile products emitted during their pyrolysis indicated on the asymmetrical disrupt of their bonds. The formation of acyclic and alicyclic monoterpene hydrocarbons, succinic anhydride, diols, alcohols, alkenes, and water was observed. It indicated mainly on the $\beta$-elimination reactions during their pyrolysis. Also, $\beta$ elimination reactions of esters are mainly expected in air. Initially, it resulted in the formation of acyclic and alicyclic monoterpene hydrocarbons, hydroxyl compounds (diols, alcohols), and its $\beta$-elimination products: aldehydes, alkenes, and water. However, the presence of oxygen in the medium causes the partial decarboxylation and oxygenation of aldehydes and thus the formation of alkenes and
\end{abstract}

M. Worzakowska $(\square)$

Department of Polymer Chemistry, Faculty of Chemistry, Maria

Curie-Skłodowska University, Gliniana 33 Street,

20-614 Lublin, Poland

e-mail: marta.worzakowska@ poczta.umcs.lublin.pl carbon dioxide. In addition, the beginning of evaporation of succinic anhydride was detected at $T_{\max 1}$. At $T_{\max 2}$ the evaporation of succinic anhydride, their partial decarboxylation to $\mathrm{CO}_{2}$, the small amounts of diols, alcohols, and aldehyde fragments were indicated. Finally, succinic anhydride, water, and carbon dioxide were only observed during decomposition of studied esters in air.

Keywords Long chain esters · TG/FTIR/QMS coupled method $\cdot$ Thermal degradation

\section{Introduction}

Esters of organic acids are very important group of compounds due to their properties and wide range of applications. The esters of dicarboxylic acids or esters of fatty acids are generally applied as softening agents for many polymers [1-4]. The esters of carboxylic acids and short chain aliphatic alcohols are used as solvents for paints and lacquers [5, 6]. The esters of multifunctional monomers like acrylates and methacrylates of various types, functionality, length, flexibility of spacer groups, containing heteroatoms, cyclic, aliphatic, or aromatic rings are employed as new monomers for preparation of polymeric materials differ in properties [7-16]. They find their place in coatings for flooring and furniture, optical fibers, dental restorative materials, hard and soft contact lenses, photolithography, in biomedical applications as biomembranes, blood-compatible materials, antithrombotic, or antivital agents [30, 31], to the production of porous microspheres in chromatography or as a potential component of polymer blends or composites [17-22].

The most of esters derivatives of aliphatic and aromatic carboxylic acids with alcohols or phenols with different 
structure are one of the most important groups of aroma compounds which are widely used in cosmetic, perfumery, and food industries. They are flavor and fragrance component added to many cosmetic products, cleaners and detergents, flavor additives in high temperature processing for many goods or intermediates in the production of fine chemicals, drugs, and pharmaceutical products [23-30].

To this time in the literature survey, only monoesters and diesters of acyclic terpene alcohols are known which are generally employed as flavor and fragrance compounds [24-32]. No information is available on the preparation of new, flavor, long chain esters which can be potentially applied as flavor and fragrance ingredients to many products, components using in high temperature processing due to their high thermal stability, high molecular mass, and high boiling temperature, and thus low volatility which makes their aroma more durable.

In this paper, the synthesis, characterization, and thermal properties of new, flavor, long chain esters derivatives of trans-3,7-dimethyl-2,6-octadien-1-ol have been presented. The range of their stabilities during pyrolysis and heating in oxidative atmosphere and the identification of gaseous products emitted during heating was evaluated.

\section{Experimental}

\section{Materials}

Geraniol (trans-3,7-dimethyl-2,6-octadien-1-ol, $97 \%$ ) was purchased from Fluka. Succinic anhydride (99\%) and aliphatic linear diols: ethylene glycol (EG), 1,4-buthylene glycol (GB), 1,5-propylene glycol, and 1,6-hexylene glycol (GH) were from Merck. Butylstannoic acid (catalyst) was obtained from Arkema Inc., USA. The reagents were used without further purification.

\section{Synthesis}

The new, flavor, long chain esters were synthesized during esterification process of trans-3,7-dimethyl-2,6-octadien-1ol, succinic anhydride, and suitable aliphatic linear diol. As diols, ethylene glycol (EG), 1,4-buthylene glycol (GB), 1,5-pentylene glycol (GP), and 1,6-hexylene glycol (GH) were applied. The reaction was carried out at $135-140{ }^{\circ} \mathrm{C}$ under reduced pressure. The reagents were used at the molar ratio of 2:2:1 (geraniol:anhydride:diol) in the presence of catalyst. The progress of the reaction was monitored by the determination of the residual acid content. Acid number $\left(\mathrm{mgKOH} \mathrm{g}^{-1}\right)$ was evaluated by titration of the sample against potassium hydroxide using phenolphthalein as an indicator and acetone as a solvent. The drop of an acid number below the value $5 \mathrm{mgKOH} \mathrm{g}{ }^{-1}$ was the
Table 1 Properties of new flavor, long chain esters

\begin{tabular}{llll}
\hline Ester & Viscosity/mPa s & Density/g cm & Refractive index \\
\hline Ger-BB-GE & 80.1 & 1.050 & 1.4855 \\
Ger-BB-GB & 84.2 & 1.051 & 1.4870 \\
Ger-BB-GP & 85.3 & 1.051 & 1.4875 \\
Ger-BB-GH & 86.6 & 1.052 & 1.4880 \\
\hline
\end{tabular}

indication of the process completion. After completion, the structure of the products was confirmed based on FTIR and NMR analyses. The physical properties of obtained flavor compounds: density, viscosity, and refractive index were measured, Table 1. The new esters were named as GerBB-GE (ester of geraniol-succinic anhydride-ethylene glycol), Ger-BB-GB (ester of geraniol-succinic anhydride1,4-buthylene glycol), Ger-BB-GP (ester of geraniol-succinic anhydride-1,5-propylene glycol), and Ger-BB-GH (ester of geraniol-succinic anhydride-1,6-hexylene glycol), respectively.

\section{Analytical methods}

Proton nuclear magnetic resonance $\left({ }^{1} \mathrm{H}\right.$ NMR) spectra were obtained using an NMR Brucker-Avance 300 MSL (Germany) spectrometer at $300 \mathrm{MHz}$ with deuterated chloroform $\left(\mathrm{CDCl}_{3}\right)$ as the solvent. ${ }^{1} \mathrm{H} \mathrm{NMR}$ chemical shifts in parts per million (ppm) were reported downfield from 0.00 ppm using tetramethylsilane (TMS) as an internal reference.

${ }^{13} \mathrm{C}$ NMR spectra were recorded on a Brucker 300MSL instrument (Germany). Chemical shifts were referred to chloroform serving as an internal standard.

Attenuated Total Reflection (ATR) was recorded using infrared Fourier transform spectroscopy on spectrometer Brucker TENSOR 27, equipped with diamond crystal (Germany). The spectra were recorded in the spectral range of $600-4,000 \mathrm{~cm}^{-1}$ with 16 scans per spectrum at a resolution of $4 \mathrm{~cm}^{-1}$.

Viscosity was measured by means of rotating spindle rheometer at $25{ }^{\circ} \mathrm{C}$, Brookfield, model DV-III (Germany).

Density was evaluated using a glass pycnometer with capillary fuse Gay/Lussac $(25 \mathrm{~mL})$ at $23{ }^{\circ} \mathrm{C}$.

Refractive index was determined by refractometer Carl Zeis Jena at $23{ }^{\circ} \mathrm{C}$.

Thermal analysis was carried out on a STA 449 Jupiter F1, Netzsch (Germany) under the following operational conditions: heating rate of $10{ }^{\circ} \mathrm{C} \mathrm{min}^{-1}$, a dynamic atmo-

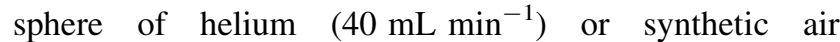
(40 $\mathrm{mL} \mathrm{min}^{-1}$ ), temperature range of $40-600{ }^{\circ} \mathrm{C}$, sample mass $\sim 10 \mathrm{mg}$, sensor thermocouple type S TG-DSC. As a reference empty $\mathrm{Al}_{2} \mathrm{O}_{3}$ crucible was used. The identification of a gas emitted during decomposition process was detected and analyzed by FT IR spectrometer TGA 585 
Brucker (Germany) and QMS 403C Aëolos (Germany) coupling on-line to STA instrument. The FTIR spectrometer with IR cell maintained at $200{ }^{\circ} \mathrm{C}$ was connected online to STA instrument by Teflon transfer line with diameter of $2 \mathrm{~mm}$ heated to $200{ }^{\circ} \mathrm{C}$. The FTIR spectra were recorded in the spectral range of $700-4,000 \mathrm{~cm}^{-1}$ with 16 scans per spectrum at a resolution of $4 \mathrm{~cm}^{-1}$. The QMS was operated with an electron impact ionizer with energy $70 \mathrm{eV}$. The measurements were performed in scan mode for $m / z$, where $m$ is the mass of molecule and $z$ is a charge of the molecule in electron charge units. The spectra were recorded in the range from 10 to $150 \mathrm{amu}$.

\section{Results and discussion}

Characterization of new, flavor, long chain esters

The theoretical structure of prepared compounds was presented in Scheme 1. The structure was confirmed using spectroscopic methods.

The basic properties of new, flavor, long chain esters are placed in Table 1. The properties of flavor compounds were not almost depended on their structure. The viscosities were in the range of 80.1-86.6 m Pas and densities were in the range of $1.050-1.052 \mathrm{~g} \mathrm{~cm}^{-3}$, respectively. The prepared esters are oils with fresh, floral aroma, insoluble in water, but well-soluble in polar and non-polar organic solvents.

\section{ATR-FTIR spectra}

The ATR-FTIR spectra of the substrates used for the preparation of esters compounds are presented in Fig. 1. The Fig. 2 shows the ATR-FTIR spectra of obtained flavor esters. The all characteristic bands for those esters are observed as was marked in Fig. 2. The disappearance of two bands responsible for the stretching vibrations characteristic for carbonyl groups $(\mathrm{C}=\mathrm{O})$ in saturated acid anhydrides at 1,772 and $1,855 \mathrm{~cm}^{-1}$ was clearly observed, Fig. 1 (1). The appearance of the stretching vibrations of carbonyl groups in esters at $1,730 \mathrm{~cm}^{-1}$ was indicated. In addition, as it is clearly visible, the lack of the absorption signals characteristic for stretching vibrations $(\mathrm{v})$ of $\mathrm{C}-\mathrm{O}$ groups in diols in the range of $1,024-1,090 \mathrm{~cm}^{-1}$ and

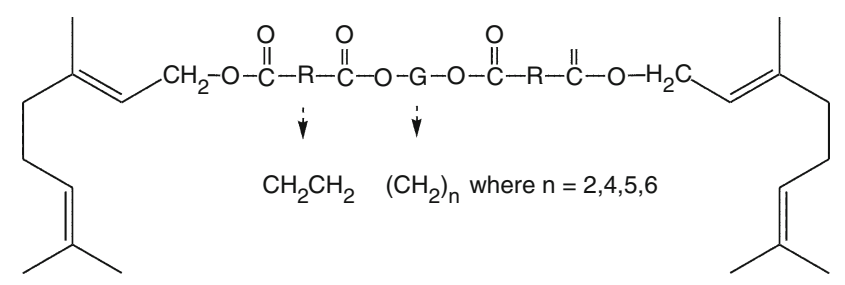

Scheme 1 Theoretical structure of obtained flavor compounds

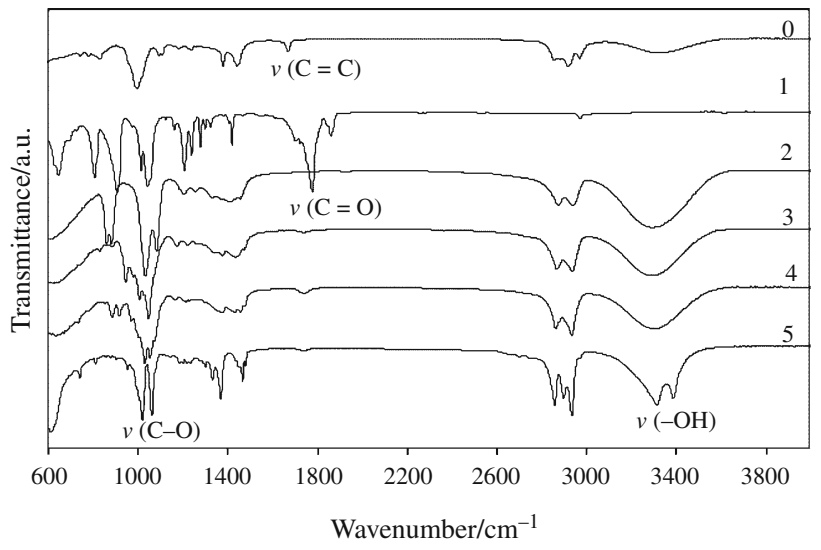

Fig. 1 ATR-FTIR spectra of starting materials: geraniol $(0)$, succinic anhydride (1), ethylene glycol (2), 1,4-buthylene glycol (3), 1,5pentylene glycol (4), 1,6-hexylene glycol (5)

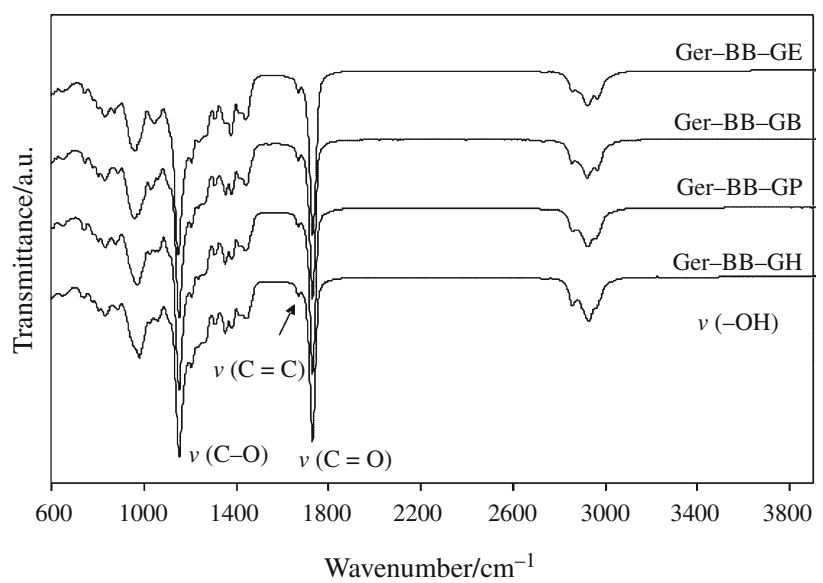

Fig. 2 ATR-FTIR spectra of new, flavor compounds

appearance of the bands in the range of $1,154-1,308 \mathrm{~cm}^{-1}$ describing the stretching vibrations of $\mathrm{C}-\mathrm{O}$ bonds for esters of aliphatic acids is indicated. The disappearance of absorption bands for hydroxyl groups of geraniol at $3322 \mathrm{~cm}^{-1}$, as well as stretching vibrations of hydroxyl groups of diols at $3,273 \mathrm{~cm}^{-1}$ (ethylene glycol), at $3,267 \mathrm{~cm}^{-1}$ (1,4-buthylene glycol), at $3,273 \mathrm{~cm}^{-1}(1,5-$ pentylene glycol) and at $3,303-3,383 \mathrm{~cm}^{-1}$ (1,6-hexylene glycol) was observed. It confirmed that the functional groups of terpene alcohol, acid anhydride, and diols were fully consumed during the esterification process, and thus the formation of the desirable products was observed.

\section{${ }^{1} \mathrm{H}$ NMR spectra}

The all protons corresponding to the structure of flavor esters are present, Fig. 3. The resonance signals attributed to the protons assigned to carbon-carbon double bonds in ester structures: $\delta=5.05-5.15 \mathrm{ppm}$ and $\delta=5.30-5.40 \mathrm{ppm}(\mathrm{e}$, f) are clearly visible. The signals characteristic for the 


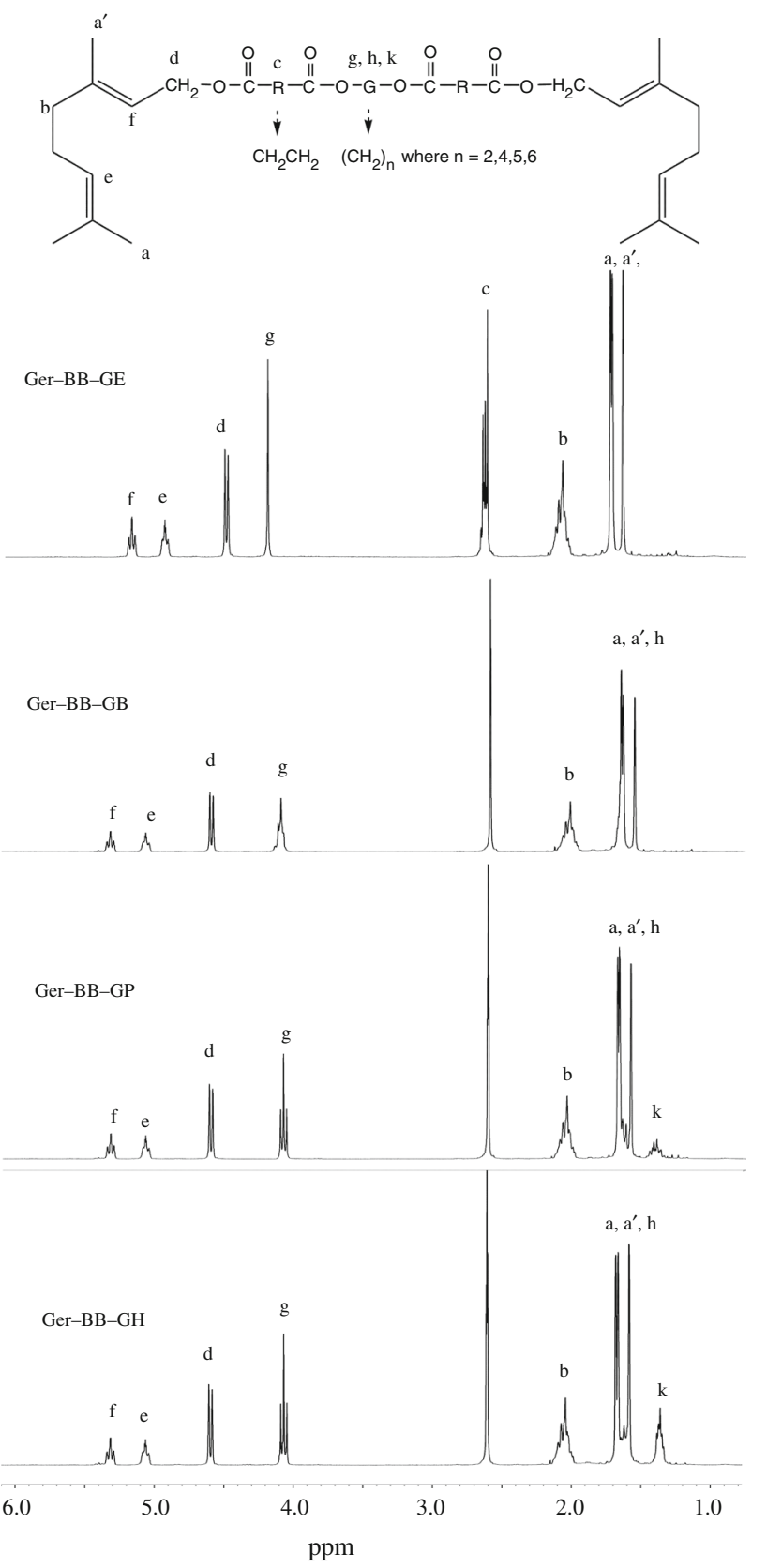

Fig. $3{ }^{1} \mathrm{H}$ NMR spectra of new, flavor compounds

protons from $-\mathrm{CH}_{2}-$ groups at $2.0-2.10 \mathrm{ppm}$ (b) and the protons from $-\mathrm{CH}_{3}$ groups of geraniol in the range of $1.60-1.75 \mathrm{ppm}\left(\mathrm{a}, \mathrm{a}^{\prime}\right)$ are observed. In addition, the protons characteristic for aliphatic $\mathrm{CH}_{2}$ - groups coming from succinic anhydride at $2.60-2.70 \mathrm{ppm}$ (c) are indicated. Also, the protons for aliphatic $-\mathrm{CH}_{2}$ groups in the esters structure from diols at $4.35 \mathrm{ppm}$ (for ethylene glycol, g), at 1.55 and $4.15 \mathrm{ppm}$ (for 1,4-buthylene glycol, g, h), and at 1.3, 1.55 and $4.1 \mathrm{ppm}$ (for 1,5-pentylene and 1,6-hexylene glycol, g, $\mathrm{h}, \mathrm{k})$ are observed. The existence of the resonance signals for $-\mathrm{CH}_{2}$ - in ester at 4.60 and at $4.1-4.30 \mathrm{ppm}$ and the absence of the resonance signals for methylene protons in trans-3,7-
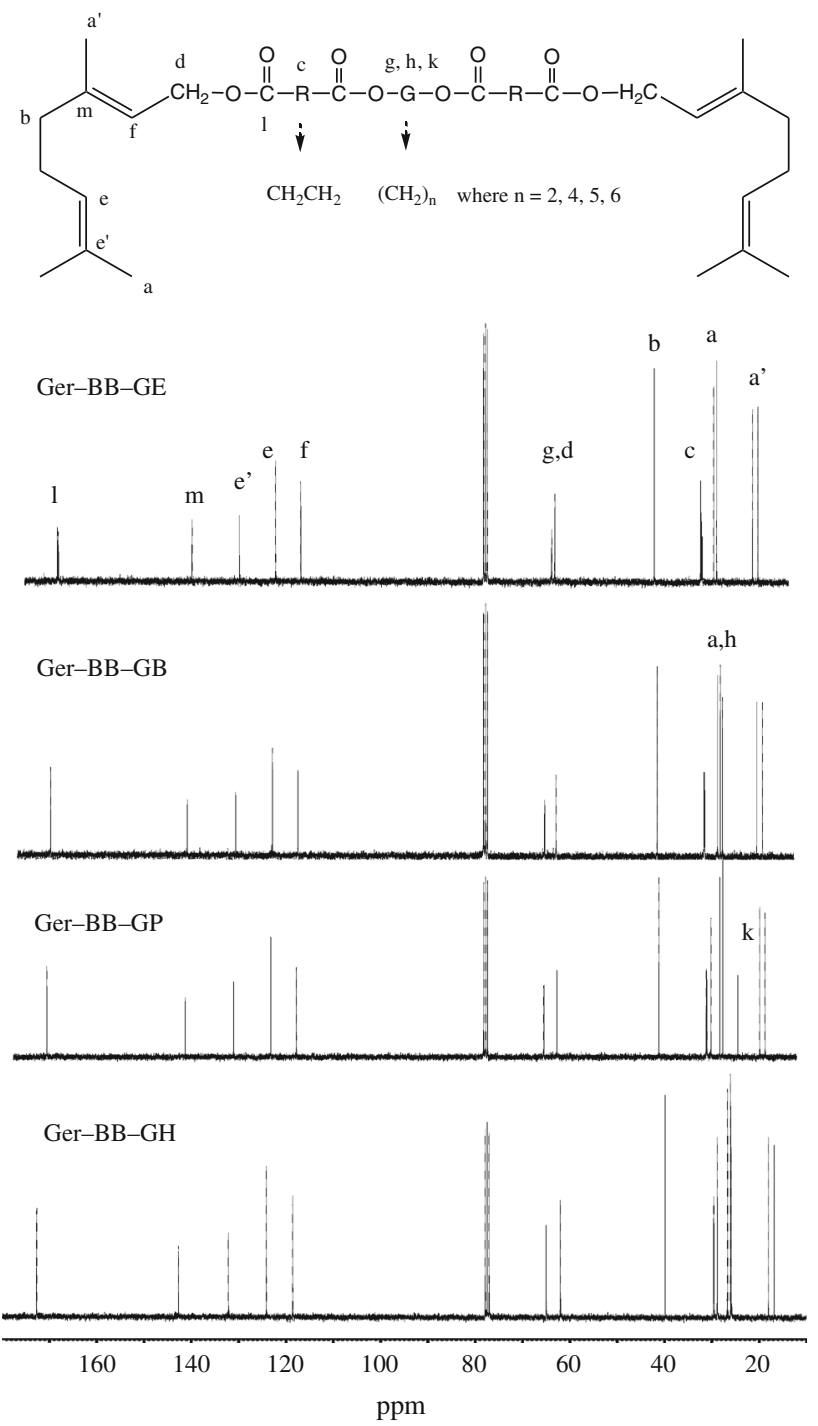

Fig. $4{ }^{13} \mathrm{C}$ NMR spectra of new, flavor compounds

dimethyl-2,6-octadien-1-ol at $4.2 \mathrm{ppm}$ and the corresponding protons for diols, e.g., at $3.70 \mathrm{ppm}$ for ethylene glycol and at $3.65 \mathrm{ppm}$ for 1,4-buthylene, 1,5-pentylene glycol and 1,6-hexylene glycol fully confirmed the formation of suitable products.

\section{CNMR spectra}

Figure 4 shows the ${ }^{13} \mathrm{C}$ NMR spectra of new, flavor compounds. As it was suspected, the spectra also confirmed the formation of the products with presumable structure.

\section{TG/DTG characterization}

The thermal properties and the mechanism of decomposition of obtained compounds are studied by the TG/DTG method in inert atmosphere (helium), Fig. 5 and in 

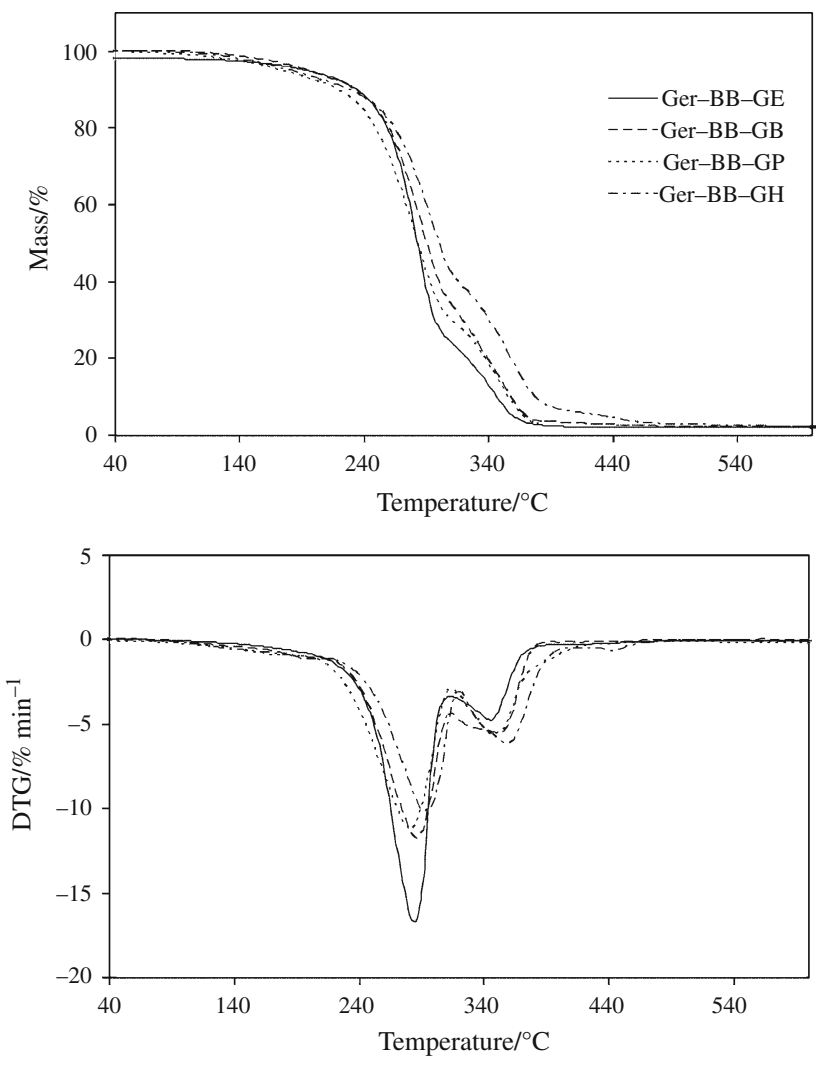

Fig. 5 TG and DTG curves in helium
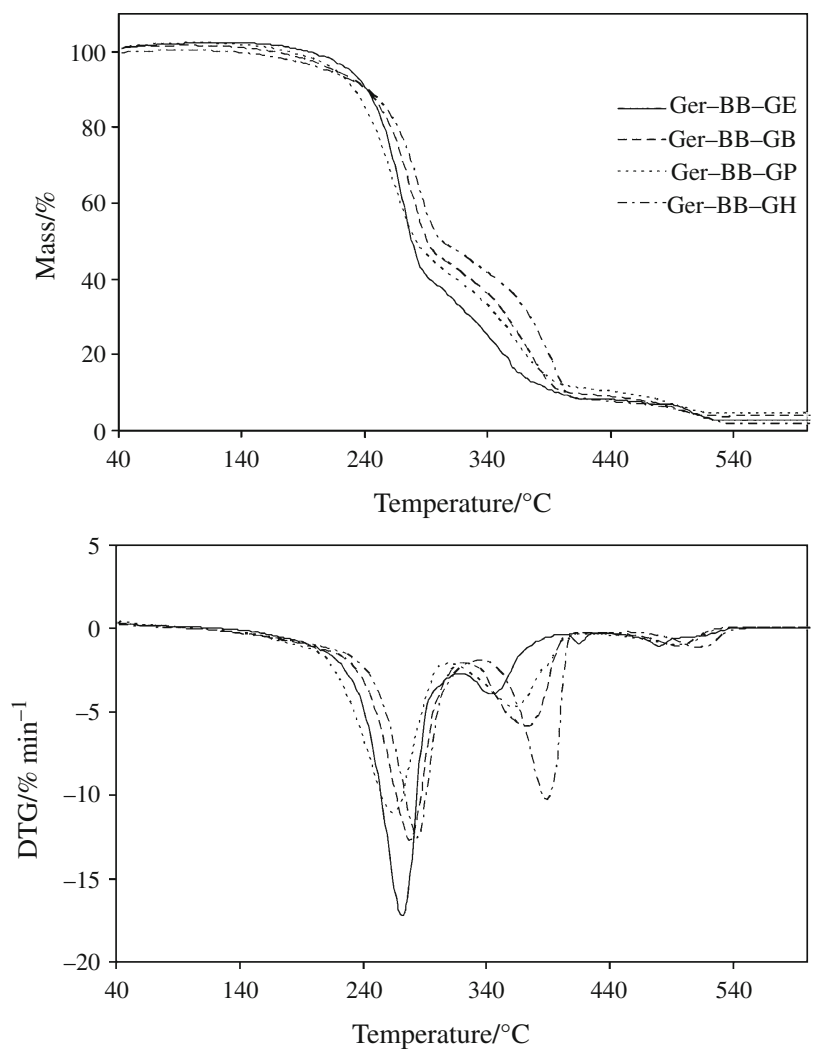

Fig. 6 TG and DTG curves in air
Table 2 TG and DTG data for obtained esters in inert atmosphere

\begin{tabular}{llllll}
\hline Ester & $\mathrm{IDT} /{ }^{\circ} \mathrm{C}$ & $T_{\max 1} /{ }^{\circ} \mathrm{C}$ & $W_{\text {loss } 1} / \%$ & $T_{\max 2} /{ }^{\circ} \mathrm{C}$ & $W_{\text {loss } 2} / \%$ \\
\hline Ger-BB-GE & 195 & 285 & 75.1 & 346 & 23.1 \\
Ger-BB-GB & 195 & 286 & 67.6 & 354 & 30.6 \\
Ger-BB-GP & 190 & 284 & 63.2 & 356 & 34.9 \\
Ger-BB-GH & 186 & 293 & 61.7 & 360 & 36.4 \\
\hline
\end{tabular}

Table 3 TG and DTG data for obtained esters in oxidative atmosphere

\begin{tabular}{llllllll}
\hline Ester & $\begin{array}{l}\text { IDT/ } \\
{ }^{\circ} \mathrm{C}\end{array}$ & $\begin{array}{l}T_{\max 1} / \\
{ }^{\circ} \mathrm{C}\end{array}$ & $\begin{array}{l}W_{\text {loss } 1 /} / \\
\%\end{array}$ & $\begin{array}{l}T_{\max 2} / \\
{ }^{\circ} \mathrm{C}\end{array}$ & $\begin{array}{l}W_{\text {loss2 } 2} / \\
\%\end{array}$ & $\begin{array}{l}T_{\max 3} / \\
{ }^{\circ} \mathrm{C}\end{array}$ & $\begin{array}{l}W_{\text {loss } 3} / \\
\%\end{array}$ \\
\hline $\begin{array}{l}\text { Ger-BB- } \\
\text { GE }\end{array}$ & 228 & 273 & 68.7 & 344 & 20.5 & 480 & 4.8 \\
$\begin{array}{l}\text { Ger-BB- } \\
\text { GB }\end{array}$ & 216 & 278 & 60.6 & 373 & 31.5 & 497 & 5.5 \\
$\begin{array}{l}\text { Ger-BB- } \\
\quad \text { GP }\end{array}$ & 212 & 267 & 58.6 & 365 & 32.5 & 495 & 5.6 \\
$\begin{array}{l}\text { Ger-BB- } \\
\text { GH }\end{array}$ & 210 & 284 & 57.7 & 390 & 34.8 & 511 & 5.7 \\
\hline
\end{tabular}

oxidative atmosphere (synthetic air), Fig. 6. The data obtained based on thermogravimetric analysis are gathered in Tables 2 and 3, respectively.

The new compounds are thermally stable up to temperatures above $185^{\circ} \mathrm{C}$ (IDT) in inert atmosphere. Their thermal stability in oxidative atmosphere is higher than $210{ }^{\circ} \mathrm{C}$. The thermal decomposition of new, flavor, linear long chain esters happened at two main, non-well divided steps in helium. The first, main decomposition step was observed from c.a. $185{ }^{\circ} \mathrm{C}$ to c.a. $320{ }^{\circ} \mathrm{C}$. The mass loss was very significant from 61.7 to almost $75.1 \%$. The second step of decomposition was occurred with the mass loss from 23.1 to $36.4 \%$ with $T_{\max 2}$ in the range of $346-360{ }^{\circ} \mathrm{C}$ in dependence on the structure of ester.

The decomposition process in oxidative atmosphere occurs in three major steps. The first decomposition step appeared in temperatures ranges from 210 to $228{ }^{\circ} \mathrm{C}$ to c.a. $315-340{ }^{\circ} \mathrm{C}$ with the mass loss from 57.7 to $68.7 \%$. The second step was observed from temperatures above $315-340{ }^{\circ} \mathrm{C}$ with the mass loss from 20.5 to $34.8 \%$. The third step of decomposition with the mass loss from 4.8 to $5.7 \%$ occurred in $T_{\max 3}$.

\section{TG/FTIR/QMS characterization in helium}

To explain the thermal degradation mechanism of new, flavor, long chain esters, the TG/FTIR/QMS analysis was additionally done. The FTIR spectra of gaseous products emitted at $T_{\max 1}$ (a) and $T_{\max 2}$ (b) during pyrolysis of studied compounds are presented in Fig. 7. At $T_{\max 1}$, Fig. 7a, It is clearly visible 

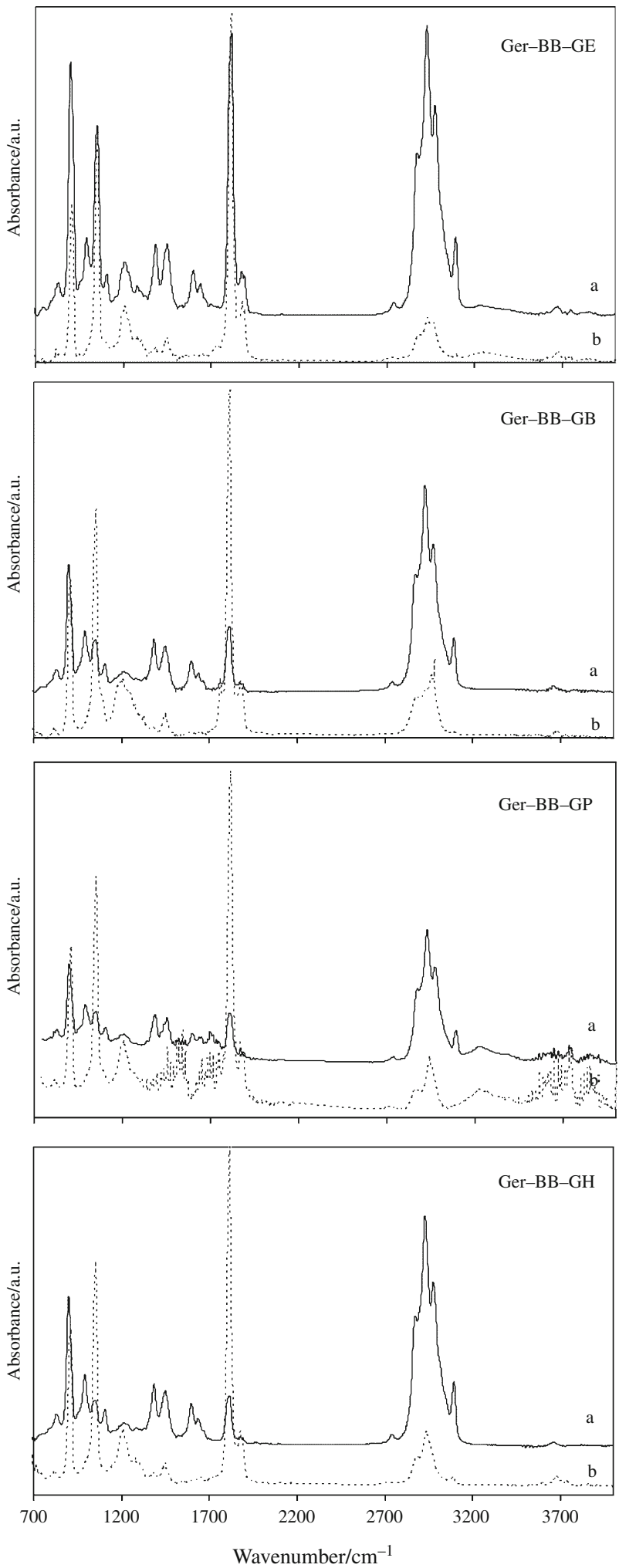

Fig. 7 FTIR spectra of gaseous products emitted in helium

the presence of absorption signals responsible for the outof-plane deformation vibrations of $=\mathrm{C}-\mathrm{H}$ for $>\mathrm{C}=\mathrm{C}-\mathrm{H}$, $-\mathrm{CH}=\mathrm{CH}_{2}$ and $-\mathrm{CH}=\mathrm{CH}$ groups at 821 and $985 \mathrm{~cm}^{-1}$, stretching vibrations of $\mathrm{C}=\mathrm{C}$ at $1,600-1,630 \mathrm{~cm}^{-1}$, and stretching vibrations of $=\mathrm{C}-\mathrm{H}$ in $\mathrm{CH}=\mathrm{CH}_{2}$ and $>\mathrm{C}=\mathrm{CH}_{2}$ groups at $3,091 \mathrm{~cm}^{-1}$. The presence of the signals for stretching $\left(2,870-2,970 \mathrm{~cm}^{-1}\right)$ and deformation $(1,380$ and $1,446 \mathrm{~cm}^{-1}$ ) vibrations of $\mathrm{C}-\mathrm{H}$ characteristic for methyl and methylene groups is also indicated. It confirmed the formation of alkene fragments as a one of the products during the first step of pyrolysis. The additional signals at $900,1,051,1,811$, and $1,870 \mathrm{~cm}^{-1}$ may be due to the stretching vibrations of $\mathrm{C}-\mathrm{O}-\mathrm{C}$ bonds and stretching vibration of carbonyl groups in five membered cyclic anhydrides. It suggests the creating of succinic anhydride during the first step of pyrolysis. However, the presence of the vibrations in the range of 1,000 $1,260 \mathrm{~cm}^{-1}$ (stretching vibration of $\mathrm{C}-\mathrm{O}$ in hydroxyl compounds) and 3,650-3,740 $\mathrm{cm}^{-1}$ (stretching vibration of $-\mathrm{OH}$ ) indicated also on the formation of hydroxyl compounds during pyrolysis like diols, alcohols, or water. In contrast at $T_{\max 2}$, Fig. $7 \mathrm{~b}$, the absorption signals for alkene fragments are faintly visible. The signals for the deformation vibrations and stretching vibrations of $\mathrm{C}-\mathrm{H}$ at $1,380-1,446 \mathrm{~cm}^{-1}$ and at $2,870-2,970 \mathrm{~cm}^{-1}$, the signals for stretching vibrations of $\mathrm{C}-\mathrm{O}-\mathrm{C}$ and $\mathrm{C}=\mathrm{O}$ at $900,1,051,1,811$ and $1,870 \mathrm{~cm}^{-1}$ suggests the evaporation of succinic anhydride without their decomposition during the second step. The presence of signals at $1,000-1,260 \mathrm{~cm}^{-1}$ (stretching vibration of $\mathrm{C}-\mathrm{O}$ in hydroxyl compounds) and $3,650-3,740 \mathrm{~cm}^{-1}$ (stretching vibration of $-\mathrm{OH}$ ) indicated also on the formation of hydroxyl compounds during pyrolysis like diols, alcohols, and water [33, 34].

The example QMS spectra of gaseous products gathered at $T_{\max 1}$ (a) and $T_{\max 2}$ (b) are presented in Fig. 8. QMS analysis clearly confirmed the results obtained from TG/FTIR studies. Regarding the structure of studied esters, the most probable alkene decomposition products formed at first decomposition step during $\beta$-elimination reactions are myrcene $(\mathrm{m} / \mathrm{z}=41$, 93, 69, 39), limonene $(m / z=68,93,39,67,41)$, ocimene $(m / z=93,41,79,91,77)$, and geraniol $(m / z=69,41,68,67$, 93). As a result of $\beta$-elimination reactions, the formation and evaporation of succinic anhydride is expected. Their existence is confirmed by the presence of corresponding ions: $\mathrm{m} / \mathrm{z}=28$, $56,26,27$. Among decomposition products one can find also diols $(m / z=31,33,29,43,42)$, their $\beta$-elimination products: allylic alcohol $(\mathrm{m} / \mathrm{z}=57,31,39,29)$, alcohols $(\mathrm{m} / \mathrm{z}=29,44$, $43,15,42)$, and their $\beta$-elimination products: alkene fragments $(m / z=27,26,25,24)$ and water $(m / z=16,17,18)$. At second decomposition step, succinic anhydride $(\mathrm{m} / \mathrm{z}=56,26,27)$, diols $((\mathrm{m} / \mathrm{z}=31,33,29,43,42)$, allylic alcohol $(\mathrm{m} / \mathrm{z}=$ $57,31,39,29)$, and water $(\mathrm{m} / \mathrm{z}=16,17,18)$ are mainly created $[33,34]$.

TG/FTIR/QMS characterization in air

The FTIR spectra of gaseous products emitted at $T_{\max 1}$ (a), $T_{\max 2}(\mathrm{~b})$, and $T_{\max 3}$ (c) during decomposition of new, 

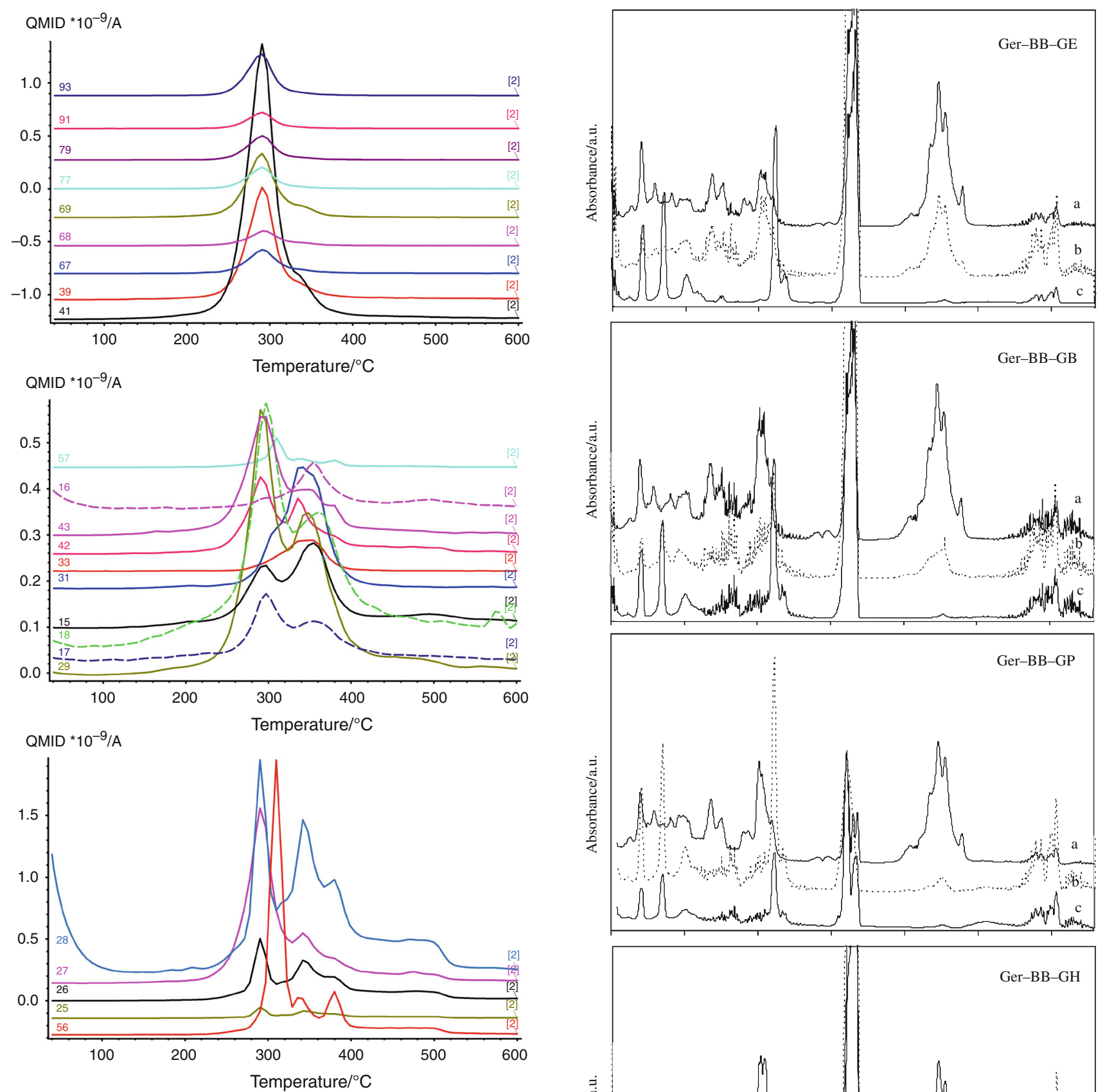

Fig. 8 QMS spectra of gaseous products emitted in helium

flavor, long chain esters in oxidative atmosphere are presented in Fig. 9. At $T_{\max 1}$, Fig. 9a, the presence of absorption signals responsible for the out-of-plane deformation vibrations of $=\mathrm{C}-\mathrm{H}$ for $>\mathrm{C}=\mathrm{C}-\mathrm{H},-\mathrm{CH}=\mathrm{CH}_{2}$, and $-\mathrm{CH}=\mathrm{CH}$ groups at 821 and $987 \mathrm{~cm}^{-1}$, stretching vibrations of $\mathrm{C}=\mathrm{C}$ at $1,600-1,620 \mathrm{~cm}^{-1}$, and stretching vibrations of $=\mathrm{C}-\mathrm{H}$ in $\mathrm{CH}=\mathrm{CH}_{2}$ and $>\mathrm{C}=\mathrm{CH}_{2}$ groups at $3,085 \mathrm{~cm}^{-1}$ is indicated. The signals for stretching $\left(2,870-2,970 \mathrm{~cm}^{-1}\right)$ and deformation $\left(1,380\right.$ and $\left.1,446 \mathrm{~cm}^{-1}\right)$ vibrations of $\mathrm{C}-\mathrm{H}$ characteristic for methyl and methylene groups are visible.

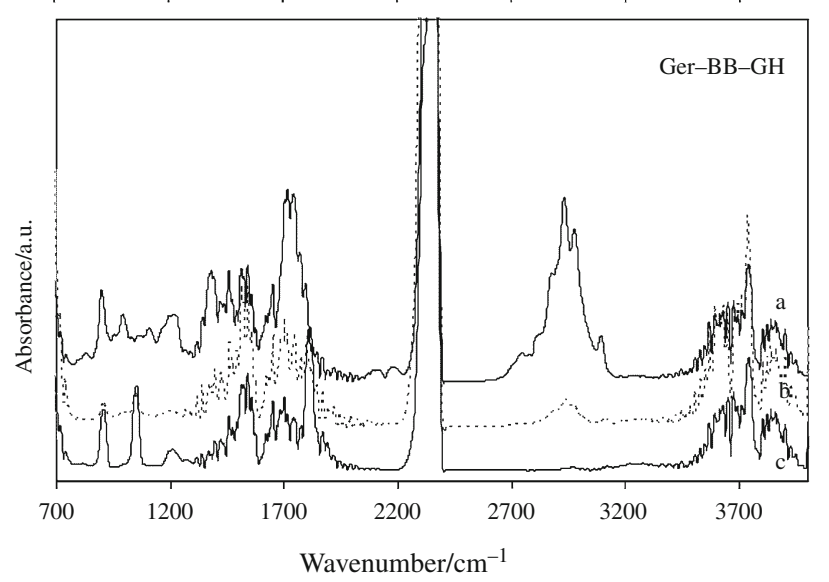

Fig. 9 FTIR spectra of gaseous products emitted in air

The presence of those bands indicated on the formation of alkene fragments as a one of the products during the first decomposition step of studied esters in air atmosphere. Also, 
the signals at $1,085-1,185 \mathrm{~cm}^{-1}$ (stretching vibrations of $\mathrm{C}-\mathrm{O}$ in hydroxyl compounds) existing together with those in the range of $2,750-2,880 \mathrm{~cm}^{-1}$ (stretching vibrations of $-\mathrm{CH}_{2}-$ in $-\mathrm{OCH}_{2}-$ or $-\mathrm{OCH}_{2} \mathrm{O}-$ groups) and $3,570-3,730 \mathrm{~cm}^{-1}$ (stretching vibration of $-\mathrm{OH}$ group) may indicate on the formation of diols or alcohols in the first step of decomposition of long chain esters. However, the signals visible as a wide peak at $1,700-1,734 \mathrm{~cm}^{-1}$ (stretching vibration of $\mathrm{C}=\mathrm{O}$ ) clearly show the creating of saturated, aliphatic aldehydes among decomposition products in air. Probably their presence is due to the $\beta$-elimination reactions of diols connecting with the oxidation process of semiproducts (organic acids) which resulted in the formation of aliphatic aldehydes and water. The bands responsible for the stretching vibrations of $-\mathrm{OH}$ in water are clearly observed in the FTIR spectra. In addition during the first step of decomposition, the signals with high intensity connecting with carbon dioxide are appeared. It is expected that their presence is due to the oxidation process of aldehydes forming from diols in air. It causes the generating of the organic acids which are quickly undergoes decarboxylation process, and thus the corresponding alkene fragments and $\mathrm{CO}_{2}$ are produced.

At $T_{\max 2}$, Fig. $9 \mathrm{~b}$ the beginning of the evaporation process of succinic anhydride is observed. The appearance of the absorption signals at 900, 1,051, 1,811, and $1,870 \mathrm{~cm}^{-1}$ (stretching vibrations of $\mathrm{C}-\mathrm{O}-\mathrm{C}$ and $\mathrm{C}=\mathrm{O}$ groups) testified about their presence during another decomposition products as was described above.

At $T_{\max 3}$, Fig. 9c generally only the evaporation of succinic anhydride, and carbon dioxide and water which are formed during decarboxylation and partial oxidation process of an acid anhydride is observed. The presence of the bands at $900,1,051,1,811$, and $1,870 \mathrm{~cm}^{-1}$ (stretching vibrations of $\mathrm{C}-\mathrm{O}-\mathrm{C}$ and $\mathrm{C}=\mathrm{O}$ groups), at $2,329-2,358 \mathrm{~cm}^{-1}\left(\mathrm{CO}_{2}\right)$ and above $3,700 \mathrm{~cm}^{-1}$ (water) is mainly visible.

Those results were also confirmed based on the data obtained from TG/QMS analysis. The example QMS spectra of the gaseous products emitted during decomposition of studied compounds in air are shown in Fig. 10. The presence of alkene fragments like myrcene $(\mathrm{m} / \mathrm{z}=41,93,69,39)$, limonene $(\mathrm{m} / \mathrm{z}=68,93,39,67,41)$, ocimene $(\mathrm{m} / \mathrm{z}=93$, $41,79,91,77)$, citral $(\mathrm{m} / \mathrm{z}=41,69,27,39)$, and its oxidized and decarboxylation form: 2,6-dimethylhepta-1,5-diene $(\mathrm{m} / \mathrm{z}=68,67,41,39)$ is indicated at $T_{\max 1}$ from QMS spectra. Also, diols $(\mathrm{m} / \mathrm{z}=31,33,29,43,42)$, alcohol fragments $(m / z=29,44,43,15,42)$, and their $\beta$-elimination products: aldehydes, water $(m / z=16,17,18)$, and alkene fragments $(m / z=27,26,25)$ are present. In addition, the fragments formed from oxygenated aldehydes: alkenes and carbon dioxide $(m / z=44)$ are observed. Moreover, QMS
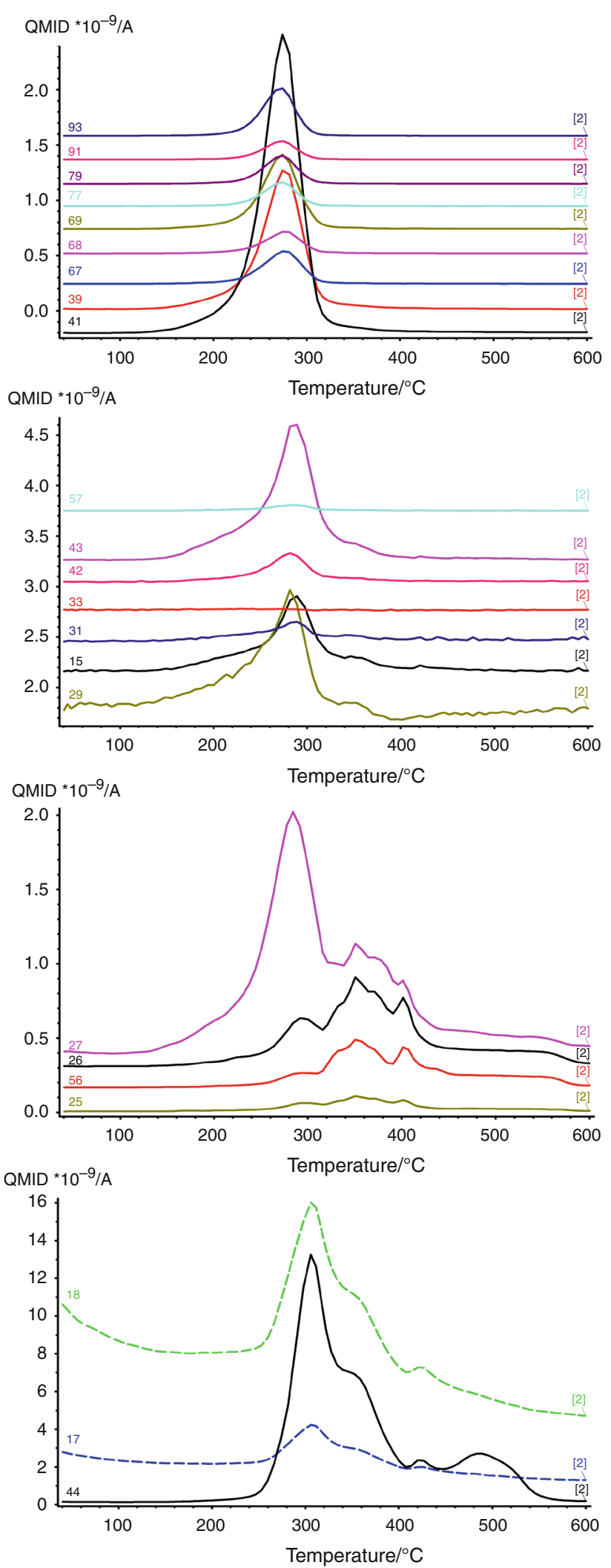

Fig. 10 QMS spectra of gaseous products emitted in air 
analysis brightly showed the beginning of the evaporation of succinic anhydride at $T_{\max 1}$. At $T_{\max 2}$, the evaporation of succinic anhydride $(\mathrm{m} / \mathrm{z}=56,26,27)$, the formation of carbon dioxide from its partial decarboxylation, the small amount of diols, alcohols, and aldehyde fragments were also detected. At $T_{\max 3}$, succinic anhydride, its partial decarboxylation products: carbon dioxide $(\mathrm{m} / \mathrm{z}=44)$ and water $(m / z=16,17,18)$ were only indicated as a decomposition products $[33,34]$.

\section{Conclusions}

The studies proved that during the catalyzed esterification process of a stoichiometric ratio of trans-3,7-dimethyl-2,6octadien-1-ol, succinic anhydride, and aliphatic, linear diols: ethylene glycol, 1,4-buthylene glycol, 1,5-pentylene glycol, and 1,6-hexylene glycol, the new, flavor, long chain esters can be prepared with high yield and purity which was confirmed by spectroscopic methods.

Those esters are high thermal stability compounds in both in inert and oxidative atmosphere. Their thermal stability in air was above $210^{\circ} \mathrm{C}$ and was higher than in helium (above $185^{\circ} \mathrm{C}$ ). The decomposition of prepared esters was run in two, non-well divided steps in helium. The mass loss was very significant from $61.7 \%$ to almost $75.1 \%$ during first decomposition step. The formation of acyclic and alicyclic monoterpene hydrocarbons: myrcene, limonene, ocimene and geraniol, succinic anhydride, diols, alcohols, allylic alcohol, alkenes, and water as the result of $\beta$-elimination reactions of esters; and their semi-products were confirmed based on TG/FTIR/QMS analysis in this step. The second step of decomposition was occurred with the mass loss from 23.1 to $36.4 \%$ which was connected with the formation of succinic anhydride, diols, allylic alcohol, and water.

The decomposition process in oxidative atmosphere occurs in three major steps. The first decomposition step was connected with the mass loss from 57.7 to $68.7 \%$. The presence of acyclic and alicyclic monoterpene hydrocarbons: myrcene, limonene, ocimene, citral, and its oxidized and decarboxylation form: 2,6-dimethylhepta-1,5-diene, diols, alcohol fragments, and their $\beta$-elimination products: aldehydes, water, carbon dioxide, and alkene fragments as a gaseous products was observed. Moreover, the beginning of the evaporation of succinic anhydride at $T_{\max 1}$ was indicated. The second step was connected with the mass loss from 20.5 to $34.8 \%$. It was jointed with the evaporation of succinic anhydride, the formation of carbon dioxide from its partial decarboxylation, the small amount of diols, alcohols, and aldehyde fragments. The third step of decomposition with the mass loss from 4.8 to $5.7 \%$ was due to the evaporation of succinic anhydride, formation of its partial decarboxylation products: carbon dioxide and water. The type of the decomposition products of new, flavor, long chain esters confirmed the $\beta$-elimination, oxygenation, and decarboxylation reactions of studied esters in oxidative atmosphere.

The studies confirmed the high thermal stability of prepared new, flavor, long chain esters. Due to this the obtained compounds can find their place as potential flavor and fragrance ingredients with more durable aroma using in high temperature processing.

Open Access This article is distributed under the terms of the Creative Commons Attribution License which permits any use, distribution, and reproduction in any medium, provided the original author(s) and the source are credited.

\section{References}

1. Raloff J. New concerns about phthalates: ingredients of common plastics; may harm boys as they develop. Science News. 2000;15: $152-4$.

2. Nakomura K. Dynamic mechanical properties of plasticized poly(vinylchloride). J Polym Sci. 1975;13:137-49.

3. Doolittle AK. Mechanism of plasticization. In: Bruins PF, editor. Plasticizer Technology. New York: Reinhold; 1965.

4. O'Brien JL. Plasticizers in Modern Plastics Encyclopedia. New York: McGraw Hill; 1988. p. 168.

5. Tumosa CS, Millard J, Erhardt D, Mecklenburg MF. Effect of solvents on the physical properties of paint films, In Preprints 12th Triennial Meeting ICOM Lisbon, ed J Bridgland. London: James \& James; 1999. pp. 347-352.

6. Erhardt D, Cunningham R, Rasanen S. Extraction of material from oil paints by solvents. In: Vanidirer PB, Goodway M, Druzik JR, Mass JL, editors. Materials issues in art and archeology VI. Boston: Materials Research Society; 2001. p. 43-52.

7. Mergo P, Gil M, Podkościelny W, Worzakowska M. Physical sorption and thermogravimetry as the methods used to analyze linear polymeric structure. Adsorption. 2013;19:851-9.

8. Fan F, Xia Z, Li Q, Li Z, Chen H. Thermal stability of phosphorus-containing styrene-acrylic copolymer and its fire retardant performance in waterborne intumescent coatings. J Therm Anal Calorim. 2013;. doi:10.1007/s10973-013-3099-y.

9. Bouyahia R, Djadoun S. Self-association effects on phase behavior and thermal properties of poly(styrene-co-itaconic acid)/ poly(butyl methacrylate-co-4-vinylpyridine) blends. J Therm Anal Calorim. 2011;106:927-36.

10. Anseth KS, Newman SM, Bowman CN. Polymeric dental composites: properties and reaction behavior of multimethacrylate dental restorations. Adv Polym Sci. 1995;122:176-217.

11. Cyr PW, Rider DA, Kulbaba K, Manners I. Photopatternable metallopolymers: photo-cross-linking and photolithography of polyferrocenylsilane methacrylates. Macromolecules. 2004;37:3959-61.

12. Nabais CRJOD, Heron BM, De Sousa HC, Gil MH, Sobral AJFN. Synthesis and characterization of co-polymers based on methyl methacrylate and 2-hexyl acrylate containing naphthopyrans for a light-sensitive contact lens. J Biomater Sci Polym Ed. 2011;22:139-52.

13. Avci D, Mathias LJ. Synthesis and photopolymerizations of new hydroxyl-containing dimethacrylate crosslinkers. Polymer. 2004; 45:1763-9.

14. Podgórski M. Synthesis and characterization of novel dimethacrylates of different chain lengths as possible dental resins. Dent Mater. 2010;26:e188-94. 
15. Andrzejewska E, Andrzejewski A. Sulfur-containing polyacrylates.IV. The effect of -S- and -O- linkages on the photo- and thermally induced polymerization of dimethacrylates. J Polym Sci Part A. 1993;31:2365-71.

16. Lin B, Zhong H, Yang Y. Synthesis and thermal analysis of linear triblock copolymers based on methacrylate ester. J Therm Anal Calorim. 2012;107:355-63.

17. Leung D, Spratt DA, Pratten J, Gulabirala K, Mordan NJ, Yound AM. Chlorhexidiene-releasing methacrylate dental composite materials. Biomaterials. 2005;26:7145-53.

18. Perez-Pineiro R, Dai S, Alvarez-Puebla R, Wigginton J, Al-Hourani BJ, Fenneri H. Synthesis of sulfur-containing aryl and Heteroaryl vinyls via Suzuki-Miyaura cross-coupling for the preparation of SERS-active polymers. Tetrahedron Lett. 2009;50:5467-9.

19. Anwar A, Burkholz T, Scherer C, Abbas M, Lehr CM, Diederich M, Jacob C. Naturally occuring reactive sulphur species, their activity against Caco-2 cells, and possible models of biochemical action. J Sulfur Chem. 2008;29:251-68.

20. Madhukar K, Sesha Sainath AV, Bikshamaiah N, Srinivas Y, Babu NM, Ashok B, Kumar DS, Rao BS. Thermal properties of single walled carbon nanotubes composites of polyamide 6/ poly(methyl methacrylate) blend system. J Therm Anal Calorim. 2013;. doi:10.1007/s10973-013-3320-z.

21. Podgórski M. Thermo-mechanical behavior and specific volume of highly crosslinked networks based on glycerol dimethacrylate and its derivatives. J Therm Anal Calorim. 2013;111:1235-42.

22. Manolea HO, Rotaru P, Manolea G, Morintale E, Rîcă R. Thermal and spectral behaviour of a light-cured methacrylate-based composite material used in dentistry. J Therm Anal Calorim. 2013;. doi:10.1007/s10973-013-3170-8.

23. Hu LH, Zou HB, Gong JX, Li HB, Yang LX, Cheng W, Zhou CX, Bai H, Guéritte F, Zhao Y. Synthesis and biological evaluation of a natural ester sintenin and its synthetic analogues. J Nat Prod. 2005;68:342-8.
24. Kristan K, Starčević Š, Brunskole M, Rižner TL, Gobec S. Cinnamates and cinnamamides inhibit fungal 17 beta-hydroxysteroid dehydrogenase. Mol Cell Endocrinol. 2006;248:239-41.

25. Stamatis H, Christakopoulos P, Kekos D, Macris BJ, Kolisis FN. Studies on the synthesis of short-chain geranyl esters catalysed by Fusarium oxysporum esterase in organic solvents. J Mol Catal B Enzym. 1998;4:229-36.

26. Bauer K, Garbe D, Surburg H. Common fragrance and flavor materials: preparation, properties and uses. New York: WileyVCh; 2001. p. 43-5.

27. Croteau R. Fragrance and flavour substances. Germany: D\&PS Verlag; 1980. p. 13-4.

28. Armstrong DW, Gillies B, Yamazaki H. In: Charalambous, editor. Flavor chemistry, trends and development. New York: Elsevier Science Publisher;1989. p.104-120.

29. United State Patent, PTC/US1995/008965 Manufacture of perfumes for laundry and cleaning. 1996.

30. United State Patent, 5652205 Perfumes for laundry and cleaning compositions. 1997.

31. Worzakowska M, Ścigalski P. TG/DSC/FTIR characterization of linear geranyl diesters. J Therm Anal Calorim. 2013;113:56-60.

32. Worzakowska M, Ścigalski P. Synthesis and thermal behavior of linear neryl diesters in inert and oxidative atmosphere. J Therm Anal Calorim. 2012;. doi:10.1007/s10973-013-3355-1.

33. Sokrates G. Infrared and Raman characteristic group frequencies, tables and charts. New York: Wiley; 2001. p. 157-67.

34. NIST chemistry webbook standard reference database number 69 , 2011, http://webbook.nist.gov/chemistry. Accessed 9 Sep 2013. 